\title{
Dynamic influence of the plane curve radius on vertical- circular overlapping lines of high-speed railway
}

\author{
Xianghui Fan ${ }^{1}$, Bin $\mathrm{Li}^{1 *}$, Yongfu Zhang ${ }^{1}$, Guoqiang $\mathrm{Du}^{1}$, and Hua Liu ${ }^{1}$ \\ ${ }^{1}$ School of Civil Engineering, Lanzhou Jiaotong University, 730070 Lanzhou, China
}

\begin{abstract}
In order to reasonably match the horizontal and vertical sections of high-speed railway lines, the vehicle-line spatial coupling model of the vertical-circular overlapping line is established, based on the multibody dynamics simulation software SIMPACK, The dynamic indexes of train passing through verticalcircular overlapping lines are calculated when the radii of different plane curves match the corresponding superelevation value. The results show that: on the vertical-circular overlapping line, it is suggested that the maximum plane curve radius is $9000 \mathrm{~m}$. The existence of the convex vertical-circular overlapping line worsens the safety of train operation and passenger comfort. The existence of the concave vertical-circular overlapping line is the opposite, but it increases rail wear and the workload of maintenance. The vertical-circular overlapping line has the most obvious influence on the vertical acceleration and the vertical Sperling index of the body. The vertical acceleration of the body is superimposed at the plane gentle circle point and the starting point of the vertical curve, which has a great impact on the stability of the train operation.
\end{abstract}

\section{Introduction}

In recent years, a large number of high-speed railways have been built in China. One of the key points of highspeed railway design is the design of horizontal and vertical sections. In the design of horizontal and vertical sections, the overlapping of horizontal and vertical sections forms complex spatial curves, which leads to the increasing of difficulties in construction and maintenance and affects the safety and stability of train operation. Therefore, the code for design of high speed railway stipulates that: Vertical curves and transition curves should not be overlapped, and vertical curves and plane circular curves should not be overlapped, too [1].

During the construction of Beijing-Shanghai highspeed railway, in order to avoid the overlapping of vertical curves and circular curves, the increasing in cost is up to $55 \%$ [2]. Therefore, in the case of the vertical-circular overlapping line, if the dynamic indexes can meet the safety and comfort requirements of high-speed railway, it will greatly save the engineering cost and bring better economic benefits. Thus, some scholars at home and abroad have carried out relevant analyses and researches on the safety and comfort of overlapping sections of horizontal and vertical curves. Songliang Lian et al. [3] verified the rationality of the parameters, which used in the overlapping line design of vertical curves and plane curves of Qinhuangdao-Shenyang high-speed railway by field experiments. And they tested the wheel-rail force, the vehicle body acceleration and stability index when the train passed. Kaiyun Wang et al. [4] based on the dynamic simulation software TTISM, analyzed the dynamic indexes of different trains passing through the horizontal and vertical sections at different speeds, and evaluated and analyzed the indexes. Chengbiao Cai et al. [5] based on the design principle of the best matching between the locomotive and the line, used the vehicle-track coupling dynamics to propose a dynamic evaluation method for horizontal and vertical sections design of high-speed railway lines. And they combined with the actual project of Beijing-Shanghai high-speed railway to carry out a comprehensive analysis and evaluation on the driving safety and riding comfort of horizontal and vertical sections of Beijing-Shanghai high-speed railway line. Guopeng Li et al. [6] analyzed the safety and stability of the locomotive with a speed of $200 \mathrm{~km} / \mathrm{h}$ through the horizontal and vertical section based on the dynamic simulation software SIMPACK. Zongsheng Sun et al. [7] established the distributed-power EUM based on SIMPACK, and analyzed the passenger comfort with the method of dynamics on the different plane curve radii of the overlapping sections of horizontal and vertical curves. In actual engineering, different plane curve radii must be matched with corresponding superelevation values [8].

In vertical-circular overlapping lines, when the radii of different plane curves match the corresponding superelevation value, the dynamic response of train operation is rarely studied at home and abroad. Therefore, based on the dynamics simulation software SIMPACK, this paper establishes spatial models of a $350 \mathrm{~km} / \mathrm{h} \mathrm{CRH} 2$ and a vertical-circular overlapping line. In order to provide reference for practical engineering, the dynamic indexes of $\mathrm{CRH} 2$ passing through the line are studied when the radii of different plane curves match the corresponding superelevation value.

\footnotetext{
${ }^{*}$ Corresponding author: Bin Li 461008013@qq.com
} 


\section{Calculation of alignment parameters}

In order to study the dynamic influence of different plane curve radii on vertical-circular overlapping lines, superelevation values matched with plane curve radii are calculated. Then, these superelevation values calculated in this paper are compared with superelevation values taken in code for design of high speed railway. According to the results of the national "Eighth Five-Year Plan" scientific and technological research project preliminary study on the plane and vertical curve parameters of high speed railway, when the plane circular curve and vertical curve are overlapped, the synthetic superelevation $h_{c}$ expression is [9]:

$$
h_{c}=\left[\frac{2 H h_{j h}}{S}+\left(\frac{g V^{2}}{R_{s h} g}\right)\right] \div\left\{\left(\frac{2 H}{S}\right)\left[1-\frac{V^{2}}{R_{s h} g}\right]\right\}
$$

Where: $h_{c}$ is the synthetic superelevation, the unit is $\mathrm{mm} ; H$ is the gravity center height of the vehicle considering spring action (CRH2 takes $1.644 \mathrm{~m}) ; h_{j h}$ is the equilibrium superelevation value of the curve, the unit is $\mathrm{mm} ; S$ is the distance between the left and right wheelrail contact points, taking $1.5 \mathrm{~m} ; V$ is the train speed, taking $350 \mathrm{~km} / \mathrm{h} ; R_{s h}$ is the radius of the vertical curve, taking $25000 \mathrm{~m} ; g$ is the acceleration of gravity, taking $9.81 \mathrm{~m} / \mathrm{s}^{2}$.

The calculation formula of equivalent under superelevation is:

$$
\Delta h_{q e}=h_{c}-h_{j h}
$$

The design speed is $350 \mathrm{~km} / \mathrm{h}$, the radius of plane circular curve is $5000 \sim 10000 \mathrm{~m}$, and the vertical curve radius is $25000 \mathrm{~m}$. The superelevation values of verticalcircular overlapping lines are shown in Table 1.

\begin{tabular}{|c|c|c|c|c|c|c|c|}
\hline \multirow{2}{*}{$\begin{array}{l}\text { The plane } \\
\text { curve } \\
\text { radius } / \mathrm{m}\end{array}$} & \multirow{2}{*}{$\begin{array}{l}\text { Synthetic } \\
\text { superelevati } \\
\text { on } / \mathrm{mm}\end{array}$} & \multirow{2}{*}{$\begin{array}{c}\text { Equivalent } \\
\text { under } \\
\text { superelevation } \\
/ \mathrm{mm}\end{array}$} & \multirow{2}{*}{$\begin{array}{l}\text { Under } \\
\text { superelevat } \\
\text { ion } / \mathrm{mm}\end{array}$} & \multirow{2}{*}{$\begin{array}{c}\text { Synthetic } \\
\text { under } \\
\text { superelevation } \\
\text { /mm }\end{array}$} & \multirow{2}{*}{$\begin{array}{l}\text { Design } \\
\text { superelevat } \\
\text { ion } / \mathrm{mm}\end{array}$} & \multicolumn{2}{|c|}{$\begin{array}{c}\text { Sum of design superelevation } \\
\text { and synthetic under } \\
\text { superelevation } / \mathrm{mm}\end{array}$} \\
\hline & & & & & & $\begin{array}{l}\text { Calculation } \\
\text { results in this } \\
\text { paper }\end{array}$ & $\begin{array}{l}\text { Code for design } \\
\text { of high speed } \\
\text { railway } \\
\end{array}$ \\
\hline $\mathrm{R}$ & $\mathrm{h}_{\mathrm{c}}$ & $\mathrm{h}_{\mathrm{qe}}$ & $\mathrm{h}_{\mathrm{q}}$ & $\mathrm{h}_{\mathrm{qe}}+\mathrm{h}_{\mathrm{q}}$ & $\mathrm{h}$ & $\mathrm{h}_{\mathrm{qe}}+\mathrm{h}_{\mathrm{q}}+\mathrm{h}$ & $\mathrm{h}_{\mathrm{qe}}+\mathrm{h}_{\mathrm{q}}+\mathrm{h}$ \\
\hline 10000 & 150.52 & 5.97 & 24.60 & 32.22 & 120 & 150.57 & - \\
\hline 9000 & 167.23 & 6.62 & 25.60 & 30.57 & 135 & 167.22 & - \\
\hline 8000 & 188.11 & 7.42 & 31.00 & 38.42 & 150 & 188.42 & 188 \\
\hline 7000 & 214.96 & 8.46 & 32.00 & 40.46 & 175 & 215.46 & 215 \\
\hline 6500 & 231.48 & 9.09 & 47.00 & 56.09 & 175 & 231.09 & 231 \\
\hline 6000 & 250.75 & 9.84 & 66.00 & 75.84 & 175 & 250.84 & 250 \\
\hline 5500 & 273.53 & 10.71 & 88.00 & 98.71 & 175 & 273.71 & 274 \\
\hline 5000 & 300.87 & 11.77 & 114.10 & 125.87 & 175 & 300.87 & - \\
\hline
\end{tabular}

Table 1. Superelevation calculation results of vertical-circular overlapping lines

It can be seen from Table 1 that when the plane curve radius changes from $5000 \mathrm{~m}$ to $10000 \mathrm{~m}$, the equivalent under superelevation value decreases from $11.77 \mathrm{~mm}$ to $5.97 \mathrm{~mm}$, which decreases by $49.3 \%$, indicating that the plane curve radius has a great influence on the equivalent under superelevation. Therefore, the influence of the vertical curve on the superelevation should be fully considered in the design of horizontal and vertical sections. It can be seen from Table 1 that the superelevation results of vertical-circular overlapping lines calculated in this paper are not much different from those specified in the code for design of high speed railway, which shows the correctness of the calculation results in this paper and also verifies the rationality and universal applicability of the superelevation values in the code.

\section{Establishment of dynamic simulation model}

Based on the existing literature, in order to analyze the dynamic response of the $350 \mathrm{~km} / \mathrm{h} \mathrm{CRH} 2$ on the verticalcircular overlapping line, a vehicle-line spatial coupling dynamics analysis model for the vertical-circular overlapping line of the high-speed railway is established.

\subsection{Establishment of vehicle dynamics model}

The CRH2 model established by SIMPACK is shown in Fig. 1, and the stiffness and damping of the model are shown in Table 2 . The simulation model consists of a body, 2 frames, 4 wheelsets, 8 axle boxes, the primary suspension and the secondary suspension. The body, frame and wheelset of the simulation model respectively consider the heave, yaw, stretch, shake head, nod and roll in space, a total of 6 degrees of freedom, and the axle box only considers nod, a total of 50 degrees of freedom.

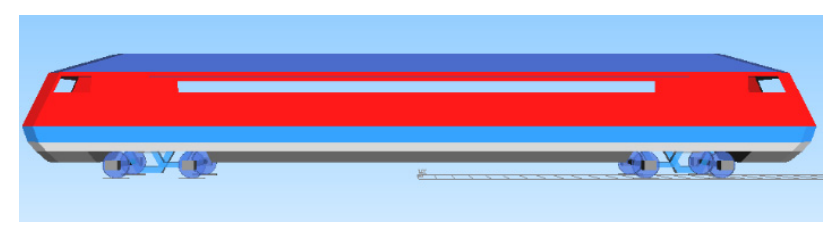

Fig. 1. Dynamic model of CRH2 
Table 2. Vehicle parameters

\begin{tabular}{cc}
\hline Name & Value \\
\hline Longitudinal stiffness of the primary axle box $/ \mathrm{N} \cdot \mathrm{m}^{-1}$ & 980000 \\
Lateral stiffness of the primary axle box $/ \mathrm{N} \cdot \mathrm{m}^{-1}$ & 980000 \\
Vertical stiffness of the primary axle box $/ \mathrm{N} \cdot \mathrm{m}^{-1}$ & 1176000 \\
Longitudinal stiffness of the primary rotating arm $/ \mathrm{N} \cdot \mathrm{m}^{-1}$ & 14700000 \\
Lateral stiffness of the primary rotating arm $/ \mathrm{N} \cdot \mathrm{m}^{-1}$ & 6500000 \\
Vertical stiffness of the primary rotating arm $/ \mathrm{N} \cdot \mathrm{m}^{-1}$ & 14700000 \\
Longitudinal stiffness of the drawbar $/ \mathrm{N} \cdot \mathrm{m}^{-1}$ & 7882000 \\
Longitudinal stiffness of the secondary spring $/ \mathrm{N} \cdot \mathrm{m}^{-1}$ & 189100 \\
Lateral stiffness of the secondary spring $/ \mathrm{N} \cdot \mathrm{m}^{-1}$ & 189100 \\
Vertical stiffness of the secondary spring $/ \mathrm{N} \cdot \mathrm{m}^{-1}$ & 220500 \\
Lateral stiffness of the secondary lateral stop $/ \mathrm{N} \cdot \mathrm{m}^{-1}$ & 630150 \\
Damping of the primary vertical shock absorber $/ \mathrm{kN} \cdot \mathrm{s} \cdot \mathrm{m}^{-1}$ & 19.6 \\
Vertical damping of the secondary spring $/ \mathrm{kN} \cdot \mathrm{s} \cdot \mathrm{m}^{-1}$ & 9.8 \\
Damping of the secondary lateral shock absorber $/ \mathrm{kN} \cdot \mathrm{s} \cdot \mathrm{m}^{-1}$ & 58.5 \\
Damping of the secondary anti hunting shock absorber $/ \mathrm{kN} \cdot \mathrm{s} \cdot \mathrm{m}^{-1}$ & 2450 \\
\hline
\end{tabular}

\subsection{Model validation}

In order to verify the correctness of the $\mathrm{CRH} 2$ simulation model, the model is simulated. Then, the vertical force and lateral force of outer rail wheel-rail obtained by simulation are compared with those measured in reference [10]. The model verification conditions are: the total length of the line is $817.94 \mathrm{~m}$, the superelevation value is $80 \mathrm{~mm}$, the length of the transition curve is $50 \mathrm{~m}$, the curve radius is $400 \mathrm{~m}$, the gauge is not widened, and the train speed is $52 \mathrm{~km} / \mathrm{h}$. Table 3 shows the comparison between the simulation results and the measured results. It can be seen from Table 3 that the maximum errors of the vertical and lateral forces between the simulation and the measured values are $5.5 \%$ and $9.6 \%$, respectively. But the errors are within $10 \%$, which indicate that the simulation model is reliable and accurate, and the basic dynamic response of the CRH2 passing through vertical-circular overlapping lines can be calculated by the simulation model.

Table 3. Comparison of simulation results and measured

\begin{tabular}{|c|c|c|c|c|}
\hline \multirow[b]{2}{*}{ Outer rail } & \multicolumn{2}{|c|}{ Measured value } & \multirow{2}{*}{$\begin{array}{l}\text { Simula } \\
\text { tion } \\
\text { calcula }\end{array}$} & \multirow{2}{*}{$\begin{array}{l}\text { Maximum } \\
\text { error }\end{array}$} \\
\hline & $\begin{array}{c}\mathrm{K} 115+9 \\
0\end{array}$ & $\mathrm{~K} 117+50$ & & \\
\hline
\end{tabular}

\begin{tabular}{ccccc}
\hline & \multicolumn{3}{c}{ tion } \\
value \\
\hline $\begin{array}{c}\text { Wheel-rail } \\
\text { vertical } \\
\text { force } / \mathrm{kN}\end{array}$ & 73.8 & 73.2 & 77.2 & $5.5 \%$ \\
$\begin{array}{c}\text { Wheel-rail } \\
\text { lateral force } \\
/ \mathrm{kN}\end{array}$ & 24.3 & 25.0 & 22.6 & $9.6 \%$ \\
\hline
\end{tabular}

\subsection{Establishment of vertical-circle overlapping line model}

The line model is an important source of system excitation and an important part of the vehicle-line coupling model [11]. The line model used in this paper is shown in Fig. 2, and the parameters in the line model are shown in Table 4.

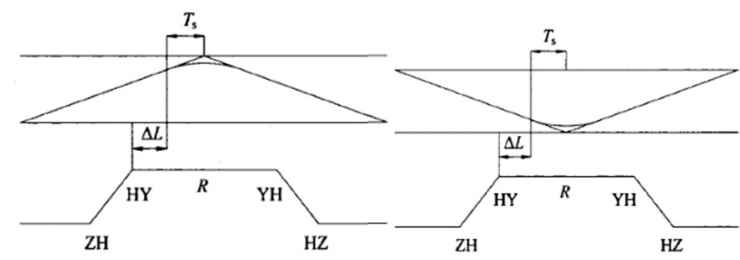

Fig. 2. Schematic diagram of plane curves overlapping with convex and concave vertical curves

Table 4. Parameters in the line model

\begin{tabular}{|c|c|c|}
\hline Section type & Curve project & value \\
\hline \multirow{3}{*}{ Vertical section } & the vertical curve radius $/ \mathrm{m}$ & 25000 \\
\hline & front-to-back slope & $10 \%$ \\
\hline & $\begin{array}{l}\text { Tangent length of the vertical } \\
\text { curve }\left(T_{\mathrm{s}}\right) / \mathrm{m}\end{array}$ & 300 (That is: $\Delta \mathrm{L}=0 \mathrm{~m}$ ) \\
\hline \multirow{4}{*}{ Plane } & the circular curve radius $/ \mathrm{m}$ & $\begin{array}{r}10000,9000,8000,7000,6500,6000, \\
5500,5000\end{array}$ \\
\hline & Length of the circular curve $/ \mathrm{m}$ & 600 \\
\hline & Transition curve type & cubic parabola \\
\hline & $\begin{array}{l}\text { Length of the transition curve } \\
\qquad / \mathrm{m}\end{array}$ & 400 \\
\hline \multirow[b]{2}{*}{$\begin{array}{l}\text { Transverse } \\
\text { section }\end{array}$} & Superelevation mode & outer rail lifting \\
\hline & Superelevation size $/ \mathrm{mm}$ & $\begin{array}{r}151,167,188,215 \\
231,250,274,301\end{array}$ \\
\hline
\end{tabular}




\section{Analysis of vehicle-line coupling dynamic calculation results}

In order to analyze the influence of the plane curve radius on the vertical-circular overlapping line, the influence of track irregularity is not considered in the line model. Under the condition of $350 \mathrm{~km} / \mathrm{h}$ driving speed and plane curve radius ranging from $5000 \mathrm{~m}$ to $10000 \mathrm{~m}$, the influence of different plane curve radii on wheel-rail dynamic action, driving safety and stability of verticalcircular overlapping line is studied.

\subsection{Analysis of dynamic effects of wheel-rail in vehicle operation}

The time-history curves of the wheel-rail dynamic action when the $\mathrm{CRH} 2$ passes through the plane curve with a radius of $5000 \mathrm{~m}$ are shown in Fig. 3. In the figure, the convex vertical-circular overlapping curve is abbreviated as convex VCO and the concave vertical-circular overlapping curve is abbreviated as concave VCO. These abbreviations are used in the following diagrams.

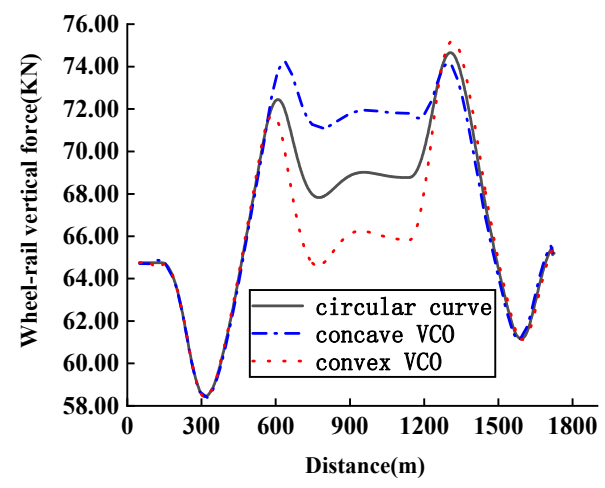

(a) Wheel-rail vertical force

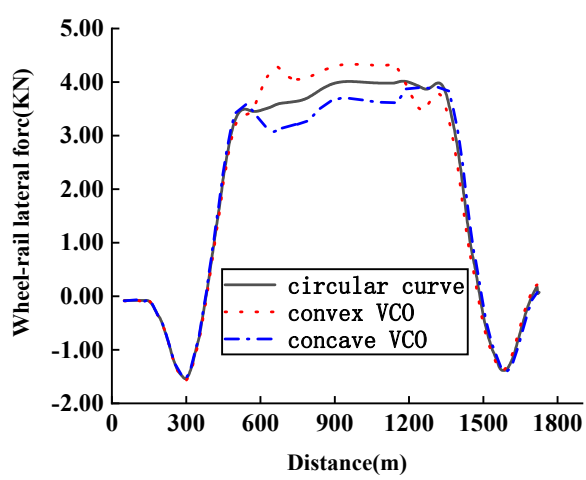

(b) Wheel-rail lateral force

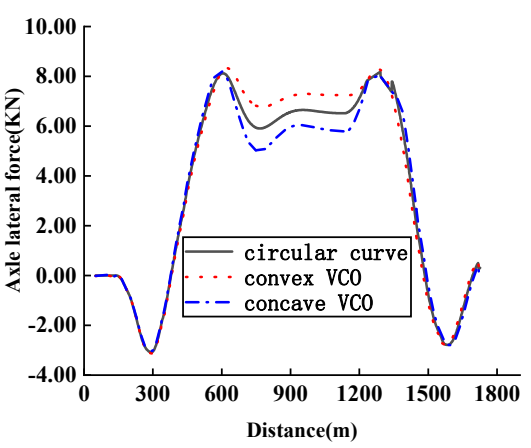

(c) Axle lateral force

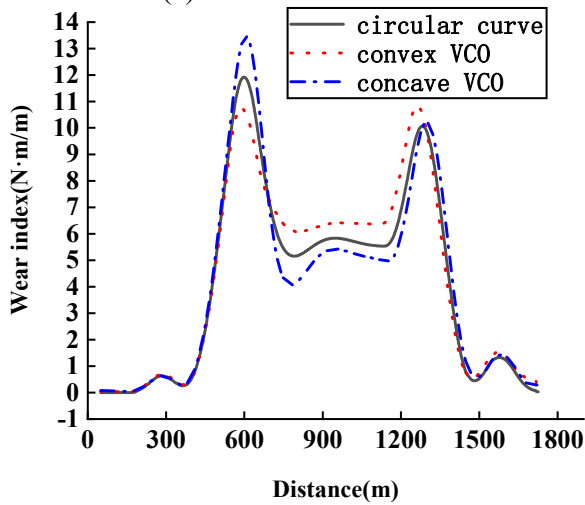

(d) Wear index

Fig. 3. Time-history curves of wheel-rail dynamic action with the radius of $5000 \mathrm{~m}$

The variation laws of wheel-rail vertical force, wheelrail lateral force, axle lateral force and wear index through different plane curve radii are shown in Fig. 4. In the figure, the maximum value of the circular curve is abbreviated as circular curve $\mathrm{M}$, the maximum value of the convex vertical-circular overlapping curve is abbreviated as convex VCOM, and the maximum value of the concave vertical-circular overlapping curve is abbreviated as concave VCOM. These abbreviations are used in the following diagrams.

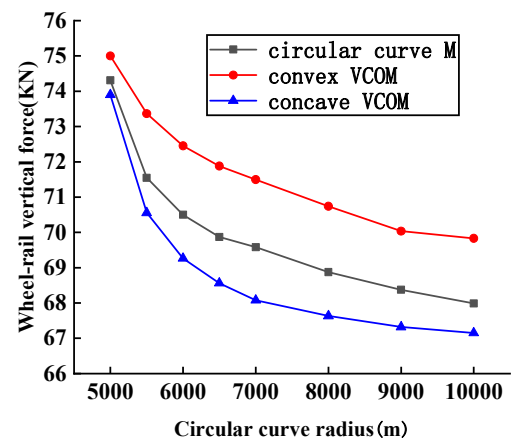

(a)Wheel-rail vertical force 


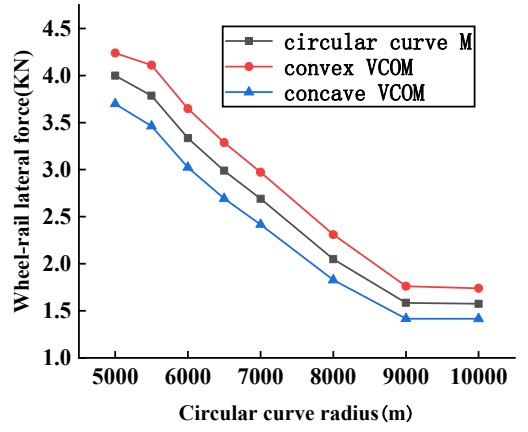

(b) Wheel-rail lateral force

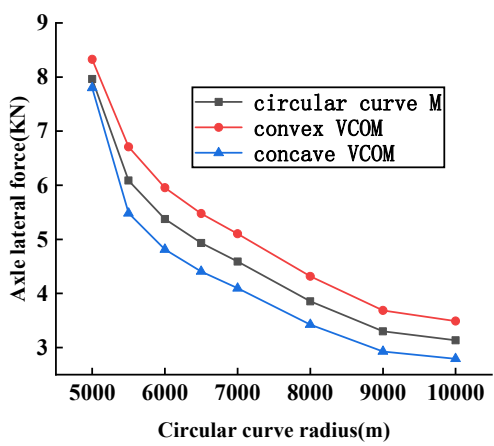

(c) Axle lateral force

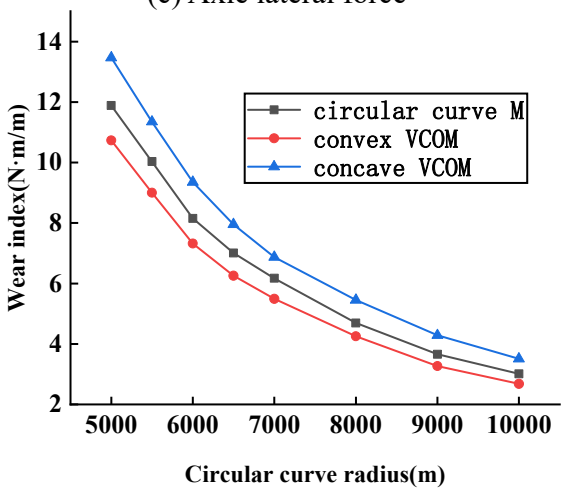

(d) Wear index

Fig. 4. Variation laws of wheel-rail dynamic action with different plane curve radii

It can be seen from Fig. 3 (a) (d) that the wheel-rail dynamic action of vehicle has obvious mutation near the starting and ending points of vertical-circular overlapping curve. It can be seen from Fig. 3 (a) that the existence of the convex vertical-circular overlapping line makes the vertical force of wheel-rail decrease. This is due to the upward centrifugal acceleration of the train on the convex vertical-circular overlapping line, resulting in the wheel load reduction. But the result of the train on the concave vertical-circular overlapping line is opposite, and wheel load reduction is not conducive to the safety of driving. It can be seen from Fig. 3 (b) and Fig. 3 (c) that compared with the plane circle curve, the wheel-rail lateral force and axle lateral force increase when the convex vertical-circular overlapping line exists, and when the concave verticalcircular overlapping line exists, the result is opposite. This shows that the existence of the convex vertical-circular overlapping line has a negative effect on the wheel-rail dynamic action, while the existence of the concave vertical-circular overlapping line can improve the wheel- rail dynamic action. It is found from Fig. 3 (d) that when the concave vertical-circular overlapping line exists, rail wear is aggravated, rail maintenance is increased and rail service life is reduced.

It can be seen from Fig. 4 (a) (d) that as the plane curve radius increases, the maximum values of wheel-rail vertical force, wheel-rail lateral force, axle lateral force, and wear index all decrease accordingly. When the plane curve radius is more than $9000 \mathrm{~m}$, the decreasing range of the maximum values is smaller and smaller, and the improvement of wheel-rail dynamic performance is less and less obvious.

\subsection{Safety analysis of vehicle operation}

In this paper, derailment coefficient and wheel unloading rate are used to analyze the safety of vehicle operation.

When the plane curve radius is $5000 \mathrm{~m}$, the corresponding safety index time-history curves are shown in Fig. 5.

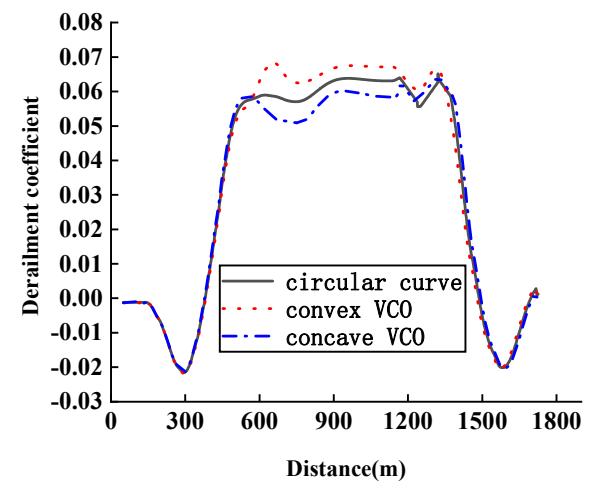

(a) Derailment coefficient

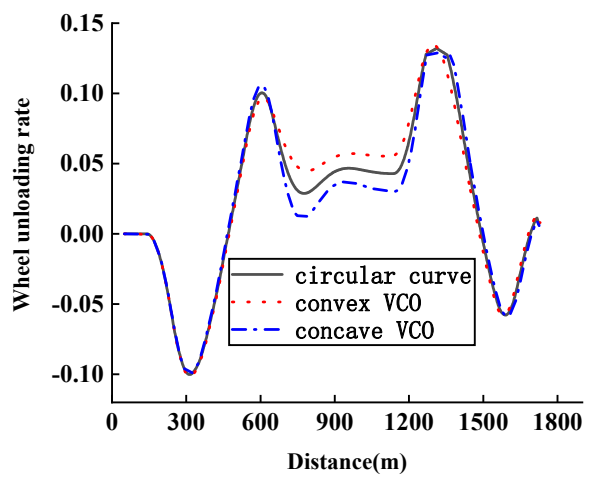

(b) Wheel unloading rate

Fig. 5. Time-history curves of safety index with the radius of $5000 \mathrm{~m}$

The variation laws of derailment coefficient and wheel unloading rate with different plane curve radii are shown in Fig. 6. 


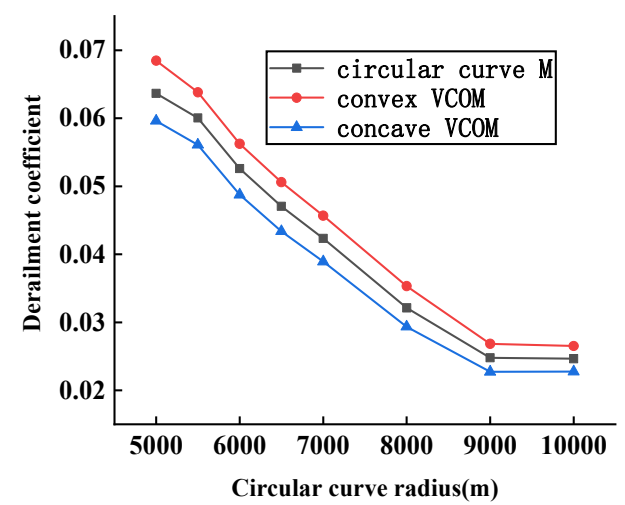

(a) Derailment coefficient

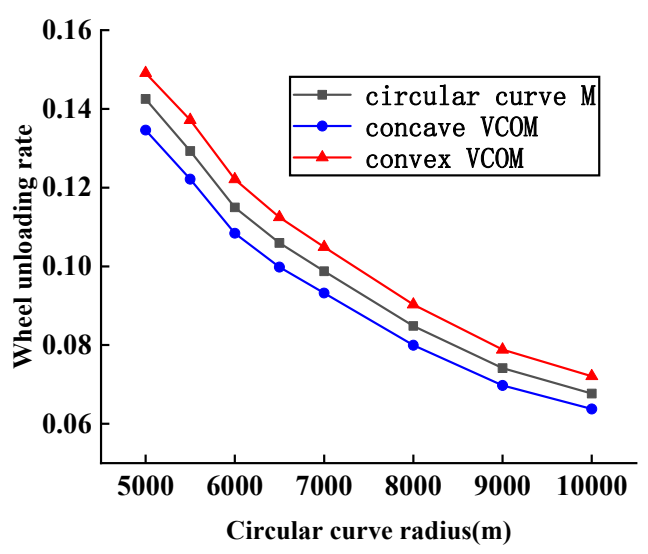

(b) Wheel unloading rate

Fig. 6. Variation laws of safety index with different plane curve radii

It can be seen from Fig.5. (a) and Fig.5. (b) that the derailment coefficient and wheel unloading rate have obvious mutation around the starting and ending points of the section of vertical-circular overlapping curve, which is unfavorable to the safety of driving. Regarding the wheel unloading rate, the existence of the convex verticalcircular overlapping line makes the wheel unloading rate increases, which is not conducive to the safety of driving. When the concave vertical-circular overlapping line exists, the result is the opposite. The calculation formula of derailment coefficient is $Q / P(Q$ is wheel-rail lateral force, $P$ is wheel-rail vertical force). When the convex verticalcircular overlapping line exists, the wheel-rail lateral force $Q$ increases, the wheel-rail vertical force $P$ decreases, and the derailment coefficient $Q / P$ increases. When the concave vertical-circular overlapping line exists, the result is the opposite. According to Fig.5, the theoretical analysis is consistent with the simulation law.

As shown in Fig.6 (a) and Fig.6 (b), the derailment coefficient and wheel unloading rate decrease with the increase of the plane curve radius. When the radius of plane curve exceeds $9000 \mathrm{~m}$, the reduction rate of derailment coefficient and wheel unloading rate is smaller and smaller, which indicates that the impact on driving safety is smaller and smaller.

\subsection{Stability analysis of vehicle operation}

The vibration degree of the vehicle during operation is mainly reflected by the stability of vehicle operation [11]. In this paper, the passenger comfort is evaluated by using the vertical acceleration, lateral acceleration, lateral Sperling index and vertical Sperling index of the vehicle body.

When the radius of the plane curve is $5000 \mathrm{~m}$, the corresponding time-history curves of stability indexes are shown in Fig.7.

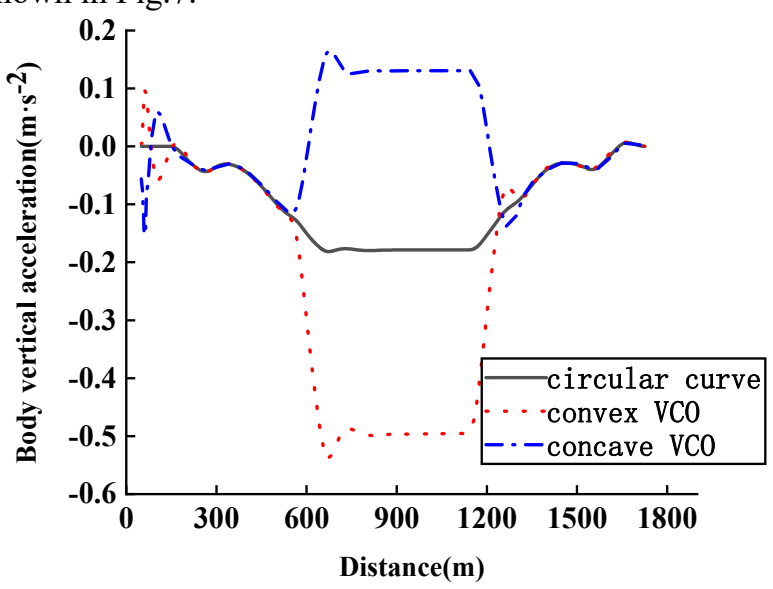

(a) Body vertical acceleration

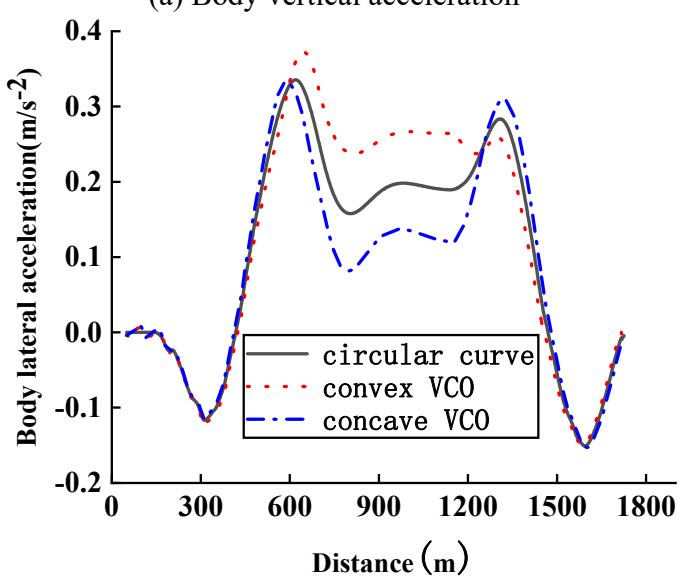

(b) Body lateral acceleration

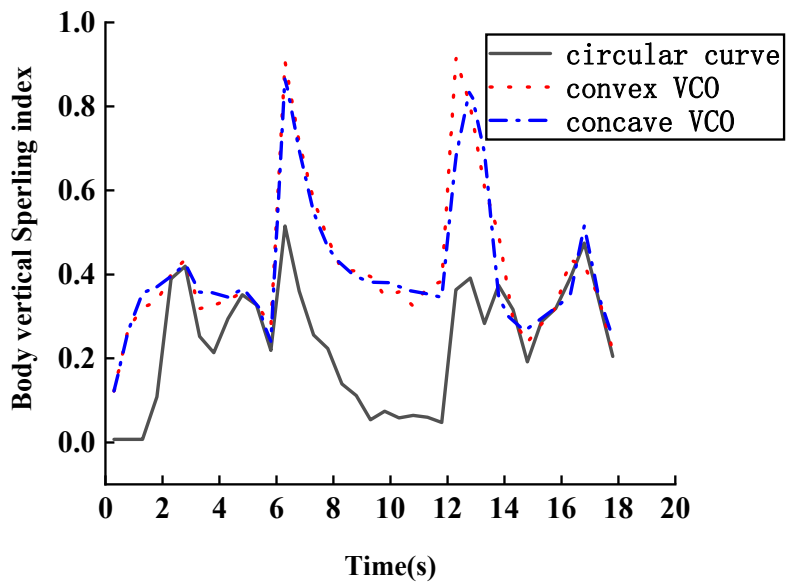

(c) Body vertical Sperling index 


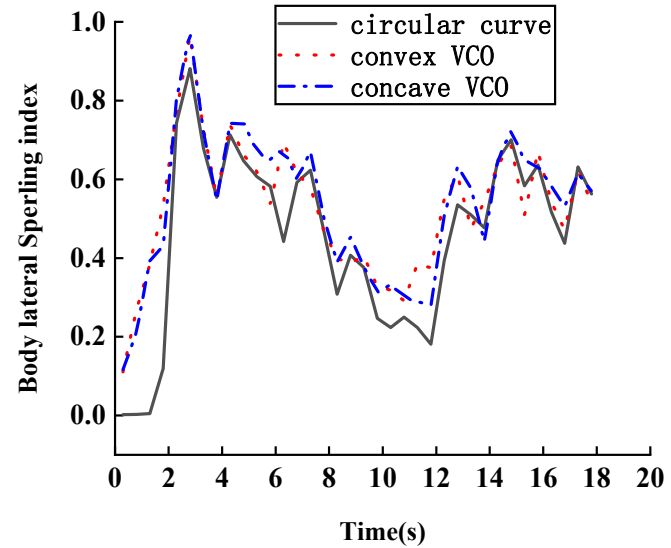

(d) Body lateral Sperling index

Fig. 7. Time-history curves of stability indexes with the radius of $5000 \mathrm{~m}$

The variation laws of stability indexes under different plane curve radii are shown in Fig.8.

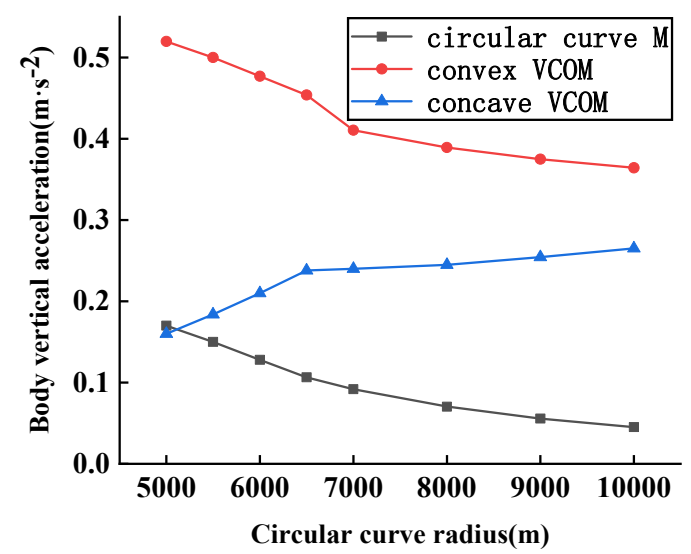

(a) Body vertical acceleration

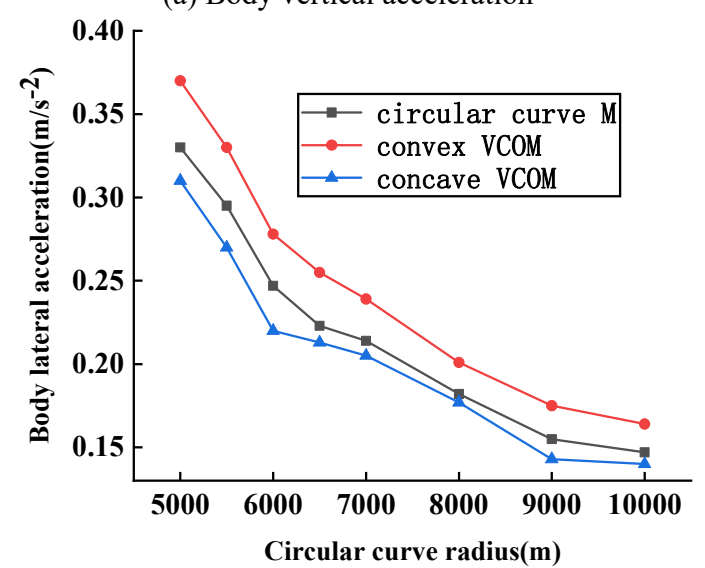

(b) Body lateral acceleration

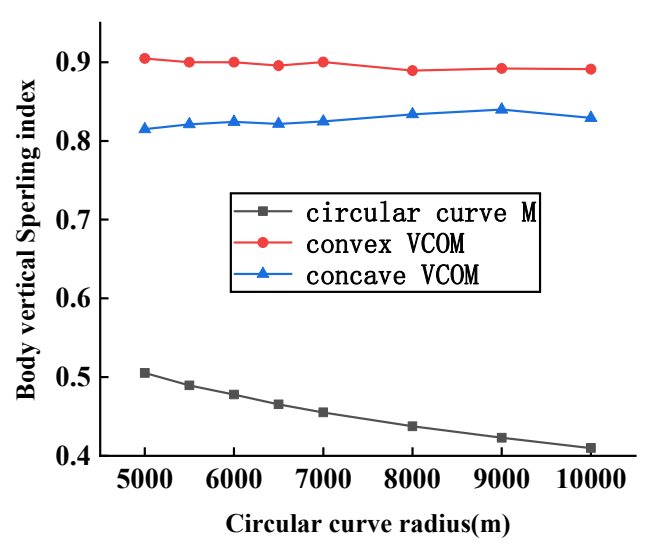

(c) Body vertical Sperling index

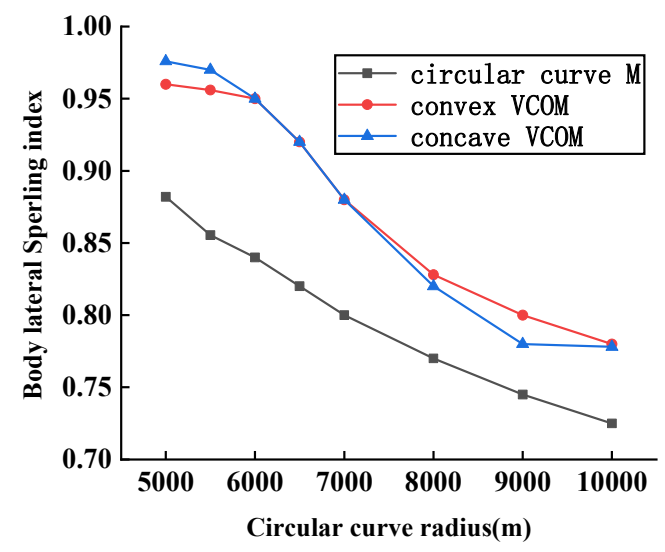

(d) Body lateral Sperling index

Fig.8. Variation laws of stability indexes under different plane curve radii

It can be seen from Fig.7 (a) that when the concave vertical-circular overlapping line exists, the vertical acceleration of the body is positive, and the body is in the overweight state. The maximum value appears near the starting point of the vertical curve, which is less than 0.3 $\mathrm{m} \cdot \mathrm{s}^{-2}$, and belongs to the superior level. When the convex vertical-circular overlapping line exists, the vertical acceleration is negative, and the body is in weightless state. The maximum value appears near the starting point of the vertical curve, which is less than $0.58 \mathrm{~m} \cdot \mathrm{s}^{-2}$, and belongs to a good grade. In the case of a circular curve only, the maximum vertical acceleration is $0.17 \mathrm{~m} \cdot \mathrm{s}^{-2}$, which appears near the intersection of easement curve and circular curve. It can be concluded from the analysis that when the intersection of easement curve and circular curve on the plane coincides with the starting point of the vertical curve, the vertical acceleration appears superposition at the coincidence point. The maximum value increases by $241 \%$, which has a great impact on the stability of the vehicle. It can be seen from Fig.7 (b) that the existence of the convex vertical-circular overlapping line worsens the body lateral acceleration, while the existence of the concave vertical-circular overlapping line improves the body lateral acceleration. It can be seen from Fig.7 (c) that when the section of vertical-circular overlapping line exists, the vertical Sperling index increases significantly. The maximum value appears at the 
start and end point of the convex vertical-circular overlapping curve. The maximum value is 0.9 , which is less than 2.5, which is excellent. It can be seen from Fig.7 (d) that the influence of the section of vertical-circular overlapping line on lateral Sperling index is not obvious.

As shown in Fig.8 (a) (d), with the increasing of the plane curve radius, the lateral acceleration and the lateral Sperling index of the body decrease. When the value of the plane curve radius exceeds $9000 \mathrm{~m}$, the decreasing tends to be flat. With the increase of the plane curve radius, the body vertical acceleration changes little, and the body vertical Sperling index is almost not affected by the plane curve radius.

\section{Conclusion}

By calculating and analyzing the dynamic indexes of CRH2 passing through vertical-circular overlapping lines with different plane curve radii, the following conclusions can be drawn.

(1) For vertical-circular overlapping lines, when the plane curve radius is over $9000 \mathrm{~m}$, the improvement effect of the plane curve radius on wheel-rail dynamic action, train operation safety and passenger comfort tends to be flat. It is suggested that the maximum plane curve radius should be $9000 \mathrm{~m}$ in the design of horizontal and vertical section of high-speed railway.

(2) The existence of the convex vertical-circular overlapping line has adverse effects on the wheel-rail dynamic action, which worsens the safety of train operation and the comfort of passengers. The existence of the concave vertical-circular overlapping line can improve the safety of train operation and the comfort of passengers, but it aggravates the rail wear, reduces the service life of rail and increases the amount of rail maintenance.

(3) The body vertical acceleration and body vertical Sperling index are affected most obviously when the vertical-circular overlapping line exists. The vertical acceleration of the body is superimposed at the plane gentle circle point and the starting point of the vertical curve, which has a great impact on the stability of the train operation.

\section{References}

1. State Railway Administration. Code for design of high speed railway[S]. Beijing: China Railway Press, (2014)

2. Long Xuyou. Study on Dynamic Effect of Alignment Parameter on Train Running Quality and Its Optimization for High-Speed Railway[D]. Beijing Jiaotong University. (2008)

3. Lian Liangsong, Chen Songlin, Li Xiangguo. Test of Vertical Curve Overlapping Plane Curve for Dedicated Passenger Traffic Railway Line[J]. Journal of the China Railway Society. 27(2): 75-79 (2005)

4. Wang Kaiyun, Zhou Weijun, Zhai Wanming, Cai Chengbiao. Research on the Reasonable Matching of Horizontal and Vertical Plane of High and Medium Speed Passenger Dedicated Line and High and Low
Speed Mixed Passenger and Freight Railway Based on Dynamics Theory[J]. Railway Standard Design. (7): 1-3 (2005)

5. Zhai Wanming, Cai Chengbiao, Wang Kaiyun. Dynamics Assessment Method for Design of High Speed Railway Plan and Profile[J]. High Speed Railway Technology. 1(1): 1-5 (2010)

6. Li Guopeng, Chen Dilai, Liu Jianxin, Chen Qing. Influence of Planar and Vertical Design on Safety and Stability of a $200 \mathrm{~km} / \mathrm{h}$ Locomotive[J]. Journal of Chongqing University of Technology(Natural Science). 28(5): 13-18, 38 (2014)

7. Sun Zongsheng, Shi Jin, Shen Xiong. Research on Dynamics Calculation and Reasonable Values of Alignment Design Parameter at Overlapping Region of Vertical Curve with Horizontal Curve on HighSpeed Railway[J]. Railway Standard Design. (6): 1-4 (2013)

8. Zhou Zhihua. Dynamic Analysis of Plane and Vertical Section Design Parameters of High Speed Passenger Dedicated Line Based on ADAMS / rail[D]. Central South University. (2010)

9. Bai Baoying. Research on the Design Standard and Application of High-Speed Railway Line Profile[J]. Railway Standard Design. (7): 4-7 (2010)

10. Wang Ning. Study on the Parameters of Small Radius Curve in High-Speed Railway Stations[D]. China Academy of Railway Sciences. (2017)

11. Zhai Wanming. Vertical-Track Coupled Dynamics [M]. Beijing: Science Press, (2007) 